\title{
TEORIA FENOMENOGRÁFICA E CONCEPÇÕES DE APRENDIZAGEM
}

\author{
Luiz Gustavo Lima Freire ${ }^{1}$
}

Resumo: O objetivo desse artigo é promover reflexões acerca das concepções de aprendizagem referenciadas pela teoria fenomenográfica, de modo a originar melhorias nas práticas de ensino-aprendizagem.

Palavras-chave: concepções; aprendizagem; fenomenografia. 
As concepções de aprendizagem refletem e simultaneamente condicionam, tanto o próprio fenômeno da aprendizagem, quanto a forma dos estudantes se comportarem em relação a ele, e ainda que não se possa dizer "diz-me o que pensas, que eu te direi quem és e o que fazes", a forma como os estudantes se comportam durante o percurso acadêmico e ao longo da vida, é em grande parte uma consequência do que pensam sobre esse fenômeno e sobre si mesmos, enquanto aprendentes. Vários autores confirmam (MARTON, 1988; SÄLJÖ, 1984; BIGGS, 1990; DUARTE, 2000) que a atuação dos estudantes é dirigida pelas suas concepções de aprendizagem, sendo válido admitir que o mapeamento conceitual desse fenômeno é prioritário, não apenas para a compreensão dos insucessos acadêmicos, como também para a promoção de mudanças das próprias concepções, tendo como objetivo último o agenciamento da autorregulação e a conquista de aprendizagens mais ricas.

A teoria fenomenográfica partilha com o construtivismo a crença na reconstrução do pensamento. O conhecimento é o resultado de uma construção cujo epicentro é o próprio estudante, a quem caberia o poder de decidir sobre os seus processos. O seu pensamento resultaria de um trabalho reflexivo e da remontagem das suas percepções, concepções, das suas ações sobre o mundo e da interação com os outros. O pensamento seria a ação refletida e interiorizada.

A perspectiva fenomenográfica comunga também com a fenomenologia, na medida em que acolhe a crença na assunção do conhecimento a partir do interior e não do exterior (como ocorre na investigação positivista). Tem como objetivo investigar a experiência que as pessoas possuem na e da realidade, a experiência vivida e o modo como representam os fenômenos. Valendo-se da razão, a fenomenologia procura descrever as operações do espírito, considerando as essências e utilizando a inteligência para perceber as suas relações lógicas. (MARTON e BOOTH, 1997).

De acordo com a teoria fenomenográfica desenvolvida na década de 70 do século XX, as concepções utilizadas pelos estudantes podem ser descritas e compreendidas. Elas se relacionam a fatores pessoais (cognitivos, afetivos e interpessoais) e a fatores ambientais (objetivos educativos, conteúdos, métodos, materiais e recursos 
educacionais) que interagem entre si, influenciam e condicionam decisivamente os processos e os resultados acadêmicos (MARTON e SÄLJÖ, 1976). De acordo com Biggs e Moore (1993, p. 452) “Um processo de aprendizagem é a resposta do sistema à interação entre os fatores de presságio de estudantes e professores". Para a fenomenografia, a aprendizagem é uma mudança qualitativa na forma de uma pessoa ver, conceitualizar, experienciar e compreender algo no mundo real. Assim, as concepções de aprendizagem podem ser definidas como a forma de representar o fenômeno da aprendizagem na consciência (MARTON e BOOTH, 1997).

Conhecer fatos e saber realizar operações, pode fazer parte dos meios para poder interpretar o mundo, mas a mudança quantitativa no conhecimento, por si própria, não altera a compreensão do fenômeno. Aprender de cor as fórmulas científicas pode ser uma das atividades dos cientistas, mas não caracteriza a sua forma de pensar. (BIGGS, 1989, p. 10).

Com efeito, a conquista de aprendizagens mais profundas e funcionais implica a compreensão das diferentes formas com as quais os intervenientes dos processos educativos representam as suas dimensões práticas e epistemológicas. E sendo a aprendizagem o fenômeno central, torna-se imprescindível a conscientização dos diversos modos utilizados para representá-la. A posse desse conhecimento poderá, sem dúvida, reconfigurar a forma de ensinar e aprender dos professores e estudantes. Trazer para o debate as concepções guardadas é refletir sobre uma prática automatizada até então. É fazer pensando e repensando, procurando afirmar posturas corretas, desconstruir costumes inadequados e reconstruir outros a partir do debate. Não é o caso de trazer para a discussão uma coisa que não existe ou que a princípio não estava lá. As concepções estão sempre e inevitavelmente presentes, e influenciam todo o processo de aprendizagem, embora, na maioria dos casos, os estudantes e os professores não se apercebam.

O "mapeamento" das representações ou a "contextualização psicológica" da aprendizagem constitui um contributivo para a 
compreensão integral desse fenômeno e para a consequente melhoria dos seus processos e produtos. Duarte (2002) particulariza que parece indispensável que as decisões relativas ao ensino se fundamentem num conhecimento da forma como os estudantes se confrontam com a aprendizagem, diz ainda que esse conhecimento é fundamental para a intervenção que pode ser realizada em nível de aconselhamento educacional, e para que os próprios estudantes compreendam e melhorem suas aprendizagens.

A palavra fenomenografia possui duas raízes: "fenômeno", que significa tudo quanto é percebido pelos sentidos ou pela consciência, e "grafia", que se refere à representação ou esquema. A sua raiz etimológica vem do grego "pháinomenon", "appearance” ou aparência e "gráphein", "descripition”, ou escrita, descrição, logo, descrição das coisas como elas se apresentam aos indivíduos (MARTON e FAI, 1999).

As primeiras experiências feitas sob o domínio fenomenográfico são da competência de Marton e Säljö (1976) que criaram esse referencial de investigação motivados pelo desejo de melhorar as aprendizagens acadêmicas. A principal tarefa da perspectiva fenomenográfica é descrever as várias representações da aprendizagem, de modo a refletir sobre esse fenômeno e poder interferir na qualidade do que se aprende. Na medida em que os professores conheçam as concepções dos seus estudantes, poderão direcionar suas aulas e incentivar o uso de estratégias de aprendizagem mais construtivas e ou adaptadas (ENTWISTLE, 1984). A fenomenografia é um modelo de investigação realista, na medida em que "[...] procura descrever e classificar as concepções das pessoas acerca da realidade, da mesma forma que um botânico pode descobrir e classificar novas espécies de plantas em alguma ilha remota" (RICHARDSON, 1999, p. 62). Adota "como unidade de investigação o modo como os indivíduos representam (graficam) a aprendizagem. O seu objeto de investigação é a variação destas formas de experiência e o seu método é o da análise qualitativa de transcrições de entrevistas semiestruturadas" (DUARTE, 2002, p. 15). Todos os dados são privilegiadamente recolhidos a partir dos próprios estudantes por meio de relatórios pessoais ou de entrevistas. O objectivo da fenomenografia é conhecer a variabilidade das concepções de aprendizagem nas consciências 
através das representações pessoais expressadas pela linguagem ou pelo discurso, diferentemente da fenomenologia que está orientada para o método e pretende conhecer a essência, encontrando um significado comum e intersubjetivo. Ambas atribuem ênfase à consciência e a reflexão sobre a experiência, porém, diferem quanto à importância atribuída ao conceito. Na fenomenografia é possível perceber claramente a diferença entre a realidade objetiva e a realidade percebida. O que importa não é o mundo propriamente, mas aquilo que os seres humanos pensam sobre ele (MARTON, 1981). A teoria fenomenográfica usa processos analíticos, associados à busca da compreensão. O seu propósito é reconhecer a forma qualitativamente diferente com que os estudantes apreendem, conceitualizam e experenciam a aprendizagem. A perspectiva é interior, o objectivo não é tanto estudar o fenômeno como ele é, mas antes, como parece a quem o vive (MARTON, 1986).

Assim, não faz sentido realizar uma apreciação ou julgamento depreciativo relativamente à perspectiva do estudante, pois, este descreve o que pensa. Sua descrição deve ser aceita no seu valor factual, dado que indica o conhecimento que tem, o significado que atribui e a forma como experencia a aprendizagem. As concepções de aprendizagem não classificam as pessoas, o que está em jogo não é puramente uma descrição, mas a descoberta das perspectivas pessoais (DUARTE, 2000). As diferentes formas de interpretar a realidade não são individuais, embora existam modos distintos de experienciar e apreender o mundo, por isso, as categorias descritivas são finitas e limitadas, apesar de comporem um sistema aberto, sensível à introdução de novas formas de experiências. Além disso, não existem descrições completas ou finais, porque a experiência não é exaustiva, ela é sempre dirigida pelos objetivos das pessoas (MARTON, 1981). Dessa forma, é possível encontrar uma estabilidade ou generalização das formas de descrever um fenômeno num dado contexto. Essa abordagem procura identificar as semelhanças e as diferenças das descrições de uma só pessoa ou entre pessoas, com vistas a utilizá-las para a compreensão de casos concretos.

A perspectiva fenomenográfica nasceu quando Marton (1976) realizou, na Universidade de Gotemburgo, um estudo em que pedia a 
um grupo de estudantes que lessem um artigo acadêmico para posteriormente responderem a algumas questões desenvolvidas para revelar seu entendimento acerca do que haviam lido. As perguntas realizadas incluíam: "Seria possível descrever como começou a leitura do texto?"; "Teve alguma coisa no texto que você considerou difícil?"; "Você achou o texto interessante ou desinteressante?". As respostas, depois de transcritas e analisadas, demonstraram que os estudantes se relacionavam com essa tarefa basicamente de duas formas: A primeira, de uma forma superficial (abordagem superficial), que consistia na leitura feita mais mecanicamente, com ênfase na forma das palavras e do texto, e a segunda, quando usavam sobretudo a compreensão, atentando para os aspectos mais gerais (abordagem profunda).

Mais tarde, os estudos identificaram, ainda, a existência de um terceiro tipo de abordagem, denominada estratégica ou de sucesso, que como o nome sugere, diz respeito àqueles casos em que os estudantes tomam a aprendizagem baseada, sobretudo, no sucesso que podem alcançar, especificamente o acadêmico, representado pelas classificações e também pelo reconhecimento por parte dos professores. Esse tipo de abordagem se caracteriza particularmente por um nível elevado de estruturação e pela utilização de estratégias de aprendizagem $^{2}$ mais sofisticadas (BIGGS e MOORE, 1993).

A diferenciação entre aprendizagens mais e menos desenvolvidas já havia sido referida pela história ${ }^{3}$. Da vasta discussão que aí se apresenta, realizaremos um recorte, apanhando uma categoria central dos argumentos de Freire (2003). A sua obra classifica a pedagogia como "bancária" ou "problematizadora", ambas determinadas pelas concepções construídas e construtoras das relações sociais. Nesse sistema de educação binário e vertical, o educador é paradoxalmente o sujeito da ação, a quem caberia prescrever e depositar os conhecimentos, enquanto o educando é o objeto, a quem caberia arquivá-los. Seguindo essa lógica, a categoria bancária se associaria a aprendizagens baseadas na acumulação do conhecimento, enquanto a categoria problematizadora, a aprendizagens baseadas na compreensão e consequentes transformações dos homens. A consciência bancária (quantitativa) "[...] pensa que quanto mais se dá mais se sabe. Mas a experiência revela que com este mesmo sistema 
só se formam indivíduos medíocres, porque não há estímulo para a criação" (FREIRE, 2003, p. 38).

$\mathrm{O}$ conceito das concepções de aprendizagem sofreu alguma variação, oscilando entre uma identificação da experiência de aprendizagem, ou seja, uma compreensão de natureza experiencial (MARTON, 1981) e a abstração de uma idéia ou de um construto. Nesse sentido, as concepções não seriam a experiência vivida concretamente, mas a forma como os indivíduos a representam (MARTON, 1983). As concepções de aprendizagem são formas qualitativamente distintas dos sujeitos exprimirem os seus pensamentos acerca da aprendizagem; relativamente a si próprios, aos seus progressos ou a qualquer outra dimensão (MARTON, 1983). Em 1988, Marton oferece mais uma variação do conceito, afirmando que esse se relaciona com o significado que uma determinada situação, tarefa de aprendizagem ou situação específica na sala de aula, possui para os indivíduos. Elas podem ser definidas como representações subjetivas e implícitas, socialmente construídas, que organizam comportamentos e representam ordenações, cumprindo a função de modelos e padrões culturais. E ainda que não sejam necessariamente refletidas, não são menos subjacentes ou atuantes na dimensão prática dos conhecimentos.

É nesse sentido que, arriscando generalizar, tomamos as concepções como categorias constitutivas de um sistema de disposições, hábitos de pensamento, sistemas de valores e classificações que perpassam as relações educativas concretas e geram estratégias e ações que ultrapassam os professores e os estudantes, sendo, portanto, construções coletivas. Por isso, pensar ou atuar sobre as concepções, ainda que seja sobre as de uma só pessoa, é na verdade, atuar sobre uma cultura ou um sistema, que regra de passagem, é muito heterogêneo. A mudança dos padrões de ensino e de aprendizagem de um contexto será tanto maior, quanto for o alcance das mudanças das concepções de aprendizagem das pessoas que compõem esse mesmo contexto. Pelo contrário, não fará sentido estimular uma ou outra concepção, mas promover a capacidade de refletir sobre o fenômeno da aprendizagem nas suas diversas modalidades, tendo sempre o objetivo de aprender mais e melhor, ainda que em alguns contextos e para algumas tarefas aprender possa implicar uma postura menos profunda. 
Em 1997, Marton e Booth defendem que a aprendizagem ou o conhecimento não se adquire do mundo (tese empirista) ou do indivíduo (tese racionalista), mas resulta da relação estabelecida entre os dois. Essa idéia relacional assenta na pressuposição de que os sujeitos e os objetos são inseparáveis, ou seja, na idéia de que os indivíduos são inexplicáveis sem o mundo e de que este só existe na medida em que pode ser experienciado. A experiência de algo é um relacionamento interno entre quem experencia e o que se experencia. Essa relação implica que nem um, nem o outro, é o que é, sem a relação entre os dois, logo, o mundo não é independente das descrições ou de quem o descreve.

A forma como as pessoas compreendem um fenômeno implica dois aspectos essenciais: "O que?" e "Como?". Para explicar essa hipótese, Marton (1988) se vale da "teoria da forma, tema e campo". Tudo o que se vê ou experencia permite uma conscientização do objeto, que é no fundo, um todo significativo emergente daquilo que o rodeia. A ciência tem uma estrutura particular, tanto quanto um tema. Esse se destaca do assunto de uma determinada maneira, porque é visto sempre de um ponto de vista. Assim, a experiência específica ou a concepção de um tópico ou objeto pode ser definida e é limitada, porque está sempre relacionada a um contexto, de modo que as peças que a compõem se relacionam ao todo. A partir da análise estrutural da consciência se poderia identificar a delimitação do tema num determinado conjunto, porque certos elementos ou aspectos de um contexto interfeririam na forma de determinar um fenômeno ou ter consciência dele. Bem como, porque se poderia também realizar um discernimento das várias partes que constituiriam um tema geral e também porque quando se experencia um fenômeno se poderia identificar e conscientizar de certos aspectos que surgiriam simultaneamente e que contribuiriam para compreendê-lo (MARTON e BOOTH, 1997). Para compreender esse princípio, os autores recorreram a Arquimedes ${ }^{4}$, considerando que os aspectos constituintes de um objeto não têm necessariamente que surgirem juntos, embora fosse importante se conscientizar deles. A nossa atenção e a conscientização de um determinado aspecto poderia ser explicada pela capacidade de variação dos objetos, sem a qual não poderíamos conceituá-los. Assim, as diferentes formas de experienciar um 
fenômeno poderiam ser entendidas a partir do seu discernimento, simultaneidade e variação na consciência (idem). O objeto tem sempre uma estrutura e essa pode ser definida como um conjunto de aspectos que mutuamente se comportam e determinam (GURTWISTCH, 1964, apud Marton et al., 1993).

A apreensão dos diferentes graus dos vários aspectos do fenômeno da aprendizagem relaciona-se com a natureza dicotômica da consciência e conduz à explicitação de alguns aspectos em detrimento dos outros, o que necessariamente não quer dizer que um aspecto implícito não possa se destacar ou vice-versa. "Qualquer situação de aprendizagem ou sistema em geral, possui uma estrutura de relevância para quem experencia, estrutura essa, que indica não só o que é visado, como também as exigências da situação e o desfecho a que ela conduz" (MARTON e BOOTH, 1997, p. 180). Essa teoria fornece, dessa forma, a possibilidade de compreender a dinâmica e a natureza contextual das concepções de aprendizagem, além de explicar a eleição de uma forma de experienciar um fenômeno, elegendo-o como uma unidade de estudo.

Bowden e Marton (2004) defendem que num mundo permanente e aceleradamente em transformação, os estudantes devem adquirir instrumentos que lhes possibilitem responderem o mais eficientemente possível às novas situações, privilegiando a aquisição de competências, muito mais do que a aquisição de conteúdos. É fundamental que os estudantes estejam atentos e saibam refletir sobre as várias realidades. O estudo das concepções de aprendizagem é, dessa forma, imprescindível na medida em que essas condicionam a forma como os fenômenos e as realidades são vistas, condicionando a maneira de atuar em cada situação específica.

A importância do estudo das concepções no âmbito do processo de ensino e aprendizagem reside na influência que essas exercem na forma como os professores e os estudantes se debruçam sobre as tarefas acadêmicas. Se quisermos compreender mais sobre a aprendizagem, então devemos considerar e nos focalizar no papel do sujeito da experiência. $\mathrm{O}$ que envolve a consideração da relação estabelecida entre ele e um determinado contexto (MARTON e BOOTH, 1997). As concepções de aprendizagem são constitutivas 
da forma como se experencia ou se aborda a aprendizagem e influenciam as relações estabelecidas com as tarefas acadêmicas (SÄLJÖ, 1982; MARTON et al., 1993). O conhecimento detalhado dos conceitos e princípios subjacentes às representações do fenômeno da aprendizagem por parte dos estudantes é fundamental para o desenvolvimento da compreensão e conscientização dos mesmos e, consequentemente, para o direcionamento ou o controle dos processos e produtos acadêmicos (BOWDEN et al., 1992).

De acordo com a fenomenografia, existem basicamente duas formas de conceber o fenômeno da aprendizagem em relação à noção de significado e à estrutura das representações que lhe são implícitas, uma que vê a aprendizagem como aquisição mecânica de conhecimentos (concepção quantitativa) e a outra como compreensão do conhecimento (concepção qualitativa). Segundo Duarte (2004), a primeira pode ser definida enquanto uma atividade memorística, como uma recolha e acumulação mecânica da informação, com o objetivo de retratá-la nas situações de avaliação. A aprendizagem é considerada como uma atividade estereotipada, exigindo relativamente pouco do indivíduo e sendo vista como "uma grande e colorida manta de retalhos a qual se vai acrescentando novos pedaços" (LAURILLARD, 1979, apud DUARTE, 2000). Essa concepção encara a aprendizagem como um modelo aditivo onde as partes se adicionam ao todo, sem a necessidade de articular, relacionar, reconstruir ou reacomodar a informação ou o conhecimento (BIGGS e MOORE, 1993). As informações podem eventualmente ser parcialmente compreendidas, atendendo apenas ao desejo de poderem ser utilizadas numa prova, embora depois possam ser esquecidas (BIGGS, 1990). A segunda concepção de aprendizagem pode ser definida como uma atividade estratégica, baseada na compreensão e ou na construção do conhecimento, conseguida através de um processo de abstração de significados, de uma interpretação pessoal da informação e do relacionamento do conhecimento formal com a realidade e a experiência, tal concepção apontaria ou resultaria num crescimento pessoal (BIGGS, 1990). Esse tipo de concepção possibilita uma interpretação, aceitação ou contestação da realidade, promovida pela alteração das suas perspectivas. Ela implicaria a utilização de um modelo 
sistemático, onde os conhecimentos novos incitariam uma nova organização pessoal e uma nova forma de se relacionar com o conhecimento, com a realidade e com as experiências pessoais (BIGGS e MOORE, 1993; MARTON e SÄLJÖ, 1997).

Enquanto os estudantes que possuem uma concepção quantitativa se preocupariam em aprender principalmente para a "escola", revelando uma aprendizagem rotineira, ingênua e elementar, manifestada por uma visão do conhecimento como algo estático, discreto e objetivo, pronto para ser utilizado na sua forma menos refinada, os estudantes que possuem uma concepção qualitativa se preocupariam principalmente em aprender para a vida e apresentariam uma aprendizagem mais sofisticada; utilizando um pensamento mais coerente, organizado e voltado para uma construção progressiva (BIGGS, 1989).

Os estudos também sugerem que aqueles estudantes que possuem uma concepção qualitativa, normalmente tendem a valorizar mais a aprendizagem (MARTON et al., 1993), o que na nossa opinião poderia levá-los a manterem-se na vida acadêmica por mais tempo, ao contrário do que aconteceria com aqueles que possuem uma concepção quantitativa.

O princípio fundamental que distingue essas duas concepções é a noção de significado. Enquanto a primeira implica a utilização de um modelo aditivo, ou seja, o todo é apenas a soma das partes, em que juntar algo a um conjunto se limitaria a ampliá-lo, a segunda pressupõe o resultado da aprendizagem como uma eventual reorganização com vistas a um novo equilíbrio (DUARTE, 2000; BIGGS e MOORE, 1993).

Também existem diferenças do ponto de vista da estrutura das representações implícitas. As respostas que manifestam uma concepção mais quantitativa são menos elaboradas, pouco estruturadas e revelam uma pequena reflexão sobre o fenômeno da aprendizagem, ao passo que as repostas mais elaboradas, mais bem estruturadas e que revelam um maior nível de reflexão, se distribuem uniformemente pelas duas concepções (BOULTON-LEWIS et al., 1996).

Embora as concepções quantitativas possam mostrar-se suficientes quando as tarefas requerem a aprendizagem de conteúdos simples ou a aquisição de competências básicas, e ainda que sejam importantes para a retenção do significado das mensagens 
compreendidas e, consequentemente, para a aplicação do conhecimento às novas situações; são deficitárias para a aprendizagem de conteúdos de nível superior. Por isso, e inclusive porque a concepção qualitativa de uma certa forma engloba a outra, existe uma hierarquia entre elas, sendo, portanto, a qualitativa considerada mais avançada do que a quantitativa (MARTON e BOOTH, 1997; CLIFF, 1998).

Mais recentemente, a investigação propôs a existência de duas novas concepções de aprendizagem: a primeira foi designada de "concepção intermédia" e se posiciona entre as concepções quantitativa e qualitativa. Representa a aprendizagem não apenas como uma memorização mecânica da informação, conseguida através de uma abordagem superficial, mas fundamentalmente como uma memorização dirigida à compreensão, conquistada pela utilização de estratégias mais profundas (DUARTE, 2000; MARTON e BOOTH, 1997).

A segunda foi denominada de "concepção comunitária" e apresenta uma vertente mais social e coletiva. Encerra a noção de aprendizagem como uma obrigação em relação à comunidade, contrariamente à habitual perspectiva individualista. Esse tipo de concepção tanto pode associar-se à qualitativa, quando os estudantes controlam suas aprendizagens e transformam-se, como pode associar-se à quantitativa, quando o que se espera é a acumulação do conhecimento para atender o objetivo de cumprir um dever social (CLIFF, 1998).

Os estudos sugeriram, ainda, a existência de uma concepção chamada de institucionalização, que apesar de pouco estudada e consistente, corresponderia a uma forma de representar a aprendizagem enquanto sucesso acadêmico, ou seja, a prova de que a aprendizagem teria ocorrido é ter passado e/ou ter obtido boas notas. Esse tipo de concepção também não ocorreria independentemente da concepção quantitativa ou qualitativa, mas associada a qualquer uma delas (BIGGS e MOORE, 1993).

Todas essas formas de representar a aprendizagem possuem um elemento comum relacionado ao aumento da capacidade de conhecer, pensar ou fazer algo através da experiência, o que subentende uma fase de aquisição e de aplicação num eixo temporal (PRAMLING, 1983; MARTON et al., 1993). Apesar disso, as concepções obedecem a uma variação que levou à construção de taxonomias descritivas 
com vista a organizar as diversas representações acerca da aprendizagem. Por meio do discurso, comparando os seus aspectos comuns e diferentes, estabeleceram-se categorias que representam as distintas formas de representar esse fenômeno. Os dois sistemas mais importantes são o de Säljö (1979, apud MARTON, 1988) e o de Marton e colaboradores (1993):

\section{O Sistema de Säljö}

Säljö (1979, apud MARTON, 1988) foi o primeiro autor a introduzir a diferenciação entre concepção quantitativa e concepção qualitativa e a considerar aspectos variáveis na sua composição. Através de um estudo qualitativo e com a utilização de entrevistas, identificou duas formas distintas de representar a aprendizagem: a primeira baseada na memorização e reprodução dos conhecimentos e segunda baseada na compreensão e na construção de uma perspectiva pessoal. Mais tarde, num outro estudo, essas duas concepções foram subdivididas em cinco categorias, que foram definidas dessa forma: aprendizagem enquanto aumento de conhecimento, exprimindo uma noção vaga, indiferenciada e pouco estruturada; enquanto memorização da informação para futura reprodução, enquanto memorização e aplicação, demonstrando que o conhecimento pode ser útil no mundo real; enquanto abstração de um significado, pressupondo uma compreensão da relação entre os vários aspectos de um conteúdo e a sua ligação com o mundo; enquanto mudança de perspectiva, revelando uma compreensão do mundo através de uma reinterpretação do conhecimento pessoal.

Essas cinco categorias, as três primeiras representativas da concepção quantitativa, chamada também de ingênua ou reprodutiva, e as duas últimas, representativas da concepção qualitativa ou como referem Norton e Crowley (1995) e Norton e Dickins (1995) desenvolvida, sofisticada ou construtiva, foram confirmadas por vários estudos posteriores. Marton e Säljö (1984) recompuseram as cinco categorias do seguinte modo: aprendizagem enquanto saber mais; enquanto memorização; enquanto aquisição de fatos ou competências 
para aplicação posterior; enquanto descoberta de significados; enquanto construção de uma filosofia pessoal.

Paralelamente e desconhecendo os sistemas propostos acima, Giorgi (1994) também identificou cinco categorias de aprendizagem que possuem total correspondência com as de Säljö, dando uma contribuição importante e consolidando o estudo fenomenográfico: aprendizagem enquanto aquisição de informação nova; enquanto repetição; enquanto aplicação; enquanto compreensão; enquanto obtenção de uma perspectiva.

\section{O Sistema de Marton e Colaboradores}

Mais alargada, a taxonomia de Marton e colaboradores (1993) baseou-se numa investigação com estudantes que pela primeira vez frequentavam a faculdade. Dada a sua importância, descreveremos mais detalhadamente cada uma das categorias, utilizando precedidamente excertos de respostas para ilustrá-las.

"[...] encher a cabeça de factos [...]" (p. 284).

1. Aumento de conhecimento - As descrições utilizadas pelos estudantes para traduzirem esse tipo de concepção são vagas, normalmente com a utilização de sinônimos para descrever a aprendizagem, como se essa possuísse um conceito evidente. $\mathrm{O}$ modo de aprender é tido como um processo de aquisição e armazenamento da informação, simplesmente por acrescento às informações anteriormente depositadas. $\mathrm{O}$ contexto em que ocorre é a vida pessoal, diferente da vida em geral.

"[...] decorar [...] algo [...] de que depois nos podemos ver livres [...]" (p. 286).

2. Memorização e reprodução - Essa categoria representa uma concepção que traduz a aprendizagem enquanto retenção de informações. Nesse sentido, aprende-se através de um processo de memorização por repetição, com vistas a poder reproduzir a informação posteriormente. O que poderia ocorrer primordialmente nas situações de avaliações escolares. 
"[...] adquirir informação, ver como ela pode ser utilizada [...]" (p. 288).

3. Aplicaçã - Essa categoria representa uma concepção que traduz a aprendizagem enquanto aquisição, armazenamento e aplicação das informações. Aprende-se recuperando e utilizando o que foi armazenado. As informações são adaptadas para serem utilizadas nas situações da vida pessoal.

"[...] apanhar o sentido [...]". (p. 288).

4. Compreensão - Essa categoria representa a aprendizagem como uma compreensão de significados ou o desenvolvimento de uma concepção sobre algo. Aprende-se através do exame crítico de uma matéria, da análise da relação entre as suas partes, da relação dessas partes com outras informações e/ou conscientizando-se de diferentes perspectivas sobre ela. A aprendizagem teria lugar especialmente nas situações escolares, sem que existam referências diretas às avaliações.

"[...] a aprendizagem [...] é sobretudo conhecer novas situações, novas vias que nos levam a conhecer e entender um pouco melhor tudo aquilo que nos rodeia, aprendemos a ter diferentes perspectivas de uma mesma realidade" (DUARTE, 2000, p. 342).

5. Reinterpretação - Essa categoria representa a aprendizagem como uma mudança da concepção que se tinha a respeito de um dado fenômeno e, eventualmente, a aprendizagem como o conhecimento de possíveis perspectivas sobre ele. Sob essa perspectiva, a reinterpretação poderia ocorrer tanto através do aumento do conhecimento, como pela generalização do que se aprendeu a outros domínios. O contexto de aprendizagem é alargado, ultrapassando a escola e os estudos.

"[...] quando compreendes mais sobre (as coisas) elas mudam [...] isso muda-te [...]" (MARTON et al., 1993, p. 292).

6. Mudança pessoa - Essa categoria também representa a aprendizagem como uma mudança das concepções sobre os fenômenos mas, além disso, e, principalmente, como uma mudança pessoal. Ver as coisas de uma forma diferente produziria uma transformação 
estabelecida através de uma relação mútua e contínua entre uma pessoa e o mundo. A possibilidade de ver as coisas de uma maneira nova promoveria um sentimento de capacidade e o papel ativo na interpretação ou agenciamento dos acontecimentos. O contexto de aprendizagem é o mais alargado possível, ultrapassando os limites da experiência pessoal ou do tempo. Segundo Duarte (2000, p.143), essa categoria replicaria a própria acepção da fenomenografia "com a sua ênfase existencialista no papel da experiência do indivíduo".

O sistema de Marton e colaboradores (1993) apresentou-se estável em diferentes contextos e foi corroborado por diversos estudos posteriores. Boulton-Lewis e colaboradores (1996), numa investigação com professores formandos de um curso sobre educação, apuraram três tipos de concepções: aprendizagem enquanto aquisição ou aumento do conhecimento; aprendizagem enquanto compreensão e aprendizagem enquanto mudança agenciadora de desenvolvimento. Cliff (1998), num estudo fenomenográfico com estudantes de uma pós-graduação, também confirmou a existência das seis concepções descritas por Marton e colaboradores (1993).

Mais recentemente, Rosário e colaboradores (2006), num estudo que pretendeu mapear as concepções de aprendizagem de um grupo de estudantes do $5 .^{\circ}$ ano de escolaridade e dos seus pais (encarregados de educação), detectaram concepções correspondentes às identificadas por Marton e colaboradores (1993), identificadas anteriormente em Portugal (Grácio, 2002), e também concepções emergentes. Os resultados demonstraram que tanto os pais quanto os filhos conceitualizam a aprendizagem como um fenômeno processual, mas enquanto os primeiros realçam mais o caráter experiencial, os segundos realçam mais o instrumental. Aprenderia-se por observação, interagindo com os outros, num processo lúdico e vivenciando as situações.

Os sistemas de categorias descritivas podem ser vistos dentro de uma hierarquia porque representam um contínuo crescimento da compreensão do fenômeno da aprendizagem.

Estudos com crianças apresentaram a existência de um aspecto desenvolvimental. Pramling (1983; 1986, apud Rosário et al., 2006) realizou uma investigação com crianças dos três aos oito anos e verificou que a sua consciência progredia no sentido do entendimento 
da aprendizagem enquanto "fazer" para o entendimento enquanto "saber", e só posteriormente enquanto "compreender".

Steketee (1997, apud Rosário et al., 2006) investigou concepções de aprendizagem em estudantes com cinco, oito e onze anos, tendo identificado seis concepções distintas e similares às concepções identificadas por Marton e colaboradores (1993): a) aprendizagem genérica; b) realização física; c) saber mais coisas; d) saber coisas mais dificeis; e) procurar o sentido e f) construir novas compreensões.

Considerando os sistemas descritos acima, pode-se estabelecer uma correspondência entre as concepções de aprendizagem dos estudantes e as metáforas propostas por Mayer (1992, apud ROSÁRIO e ALMEIDA, 2005) para representar as concepções teóricas da aprendizagem, que são:

A) Aquisição de respostas - Corresponde a uma concepção quantitativa. Marca uma perspectiva comportamentalista, na qual a aprendizagem é encarada como um processo associacionista, mecânico e repetitivo. $\mathrm{O}$ estudante desempenha um papel passivo, enquanto o professor é um conhecedor que oferece estímulos e reforços. A conduta da aprendizagem é observável e controlável.

B) Aquisição de conhecimentos - Corresponde a uma concepção qualitativa. Marca uma perspectiva neocomportamentalista, com uma ênfase no processamento das informações, nos processos mentais cognitivos, nos mecanismos internos subjacentes à conduta "mente-ordenador" e subjacentes à inteligência artificial. A aprendizagem surge da interação com o meio, como resultado de conexões entre estruturas mentais. Aprender é conquistar novos esquemas. É o professor quem transmite o conhecimento. O sujeito é cognitivo mas não controla a sua própria aprendizagem. $\mathrm{O}$ ensinoaprendizagem centra-se na informação.

C) Construção de significados - Corresponde aji uma concepção de aprendizagem enquanto mudança pessoal. Marca uma perspectiva construtivista, em que há uma centralização na modificabilidade cognitiva. O sujeito é mais ativo, autônomo e conhecedor dos seus próprios processos cognitivos. Constrói o conhecimento porque usa a experiência para compreender o "novo". 
O professor fornece pistas e chaves para essa construção. A aprendizagem consiste no aprender a aprender.

Nos últimos anos, tem-se empreendido na Faculdade de Psicologia e Ciências da Educação da Universidade de Lisboa um programa de investigação, com o objetivo de compreender as concepções de aprendizagem em geral e para diferentes atividades acadêmicas. As concepções de aprendizagem se referem aos aspectos gerais do aprender, por isso, ultrapassam a natureza das tarefas acadêmicas específicas, sendo possível refletir sobre a forma como tais concepções se exprimem referentemente a algumas dessas atividades particulares. Nesse âmbito, foram desenvolvidos estudos que pretenderam compreender as concepções de aprendizagem em geral (DUARTE, 2000) em estudantes universitários brasileiros (FREIRE, 2008) para as situações de avaliação (RENDEIRO, 2005) e para a aprendizagem com o computador (REBELO, 2005).

Duarte (2000), num estudo fenomenográfico com estudantes universitários portugueses, confirmou as categorias propostas por Marton e colaboradores (1993) identificando outras duas categorias: compreensão e aplicação, representativa de uma concepção que traduz a aprendizagem enquanto um processo de compreensão do conhecimento, associado a sua aplicação no mundo; e conjugando, que traduziria a aprendizagem como um processo resultante da conjugação entre memorização e compreensão da informação, concepção essa que também poderia ser vista como uma replicação da concepção intermédia. Esse autor detectou ainda duas novas versões das categorias aplicação e mudança pessoal. Relativamente à primeira, aprender-se-ia recuperando e utilizando o que foi adquirido ou utilizando e modificando a informação, enquanto relativamente à segunda, aprender-se-ia através de um processo de motivação pessoal, o que confirma a importância de uma motivação elevada e intrínseca, ${ }^{5}$ por parte de quem aprende.

Rendeiro (2005), num estudo com estudantes portugueses do $12^{\circ}$ ano, que pretendeu identificar as concepções de aprendizagem para as situações de avaliação considerando três momentos: antes, durante e depois da avaliação ter ocorrido, comprovou a correspondência de concepções de aprendizagem para a avaliação 
com a maioria das concepções de aprendizagem desveladas pela fenomenografia. Os resultados desse estudo apontaram que a aprendizagem face à avaliação pode ser concebida como um processo de armazenamento, memorização e aplicação da informação (forma quantitativa) quando o objetivo do estudante é reproduzir e aplicar tal informação durante o momento avaliativo. Pelo contrário, pode ser concebida de modo mais rico (forma qualitativa) quando representada enquanto processo de reestruturação do conhecimento, desenvolvimento de novas perspectivas e mudança pessoal. Para além dessas duas formas, revelou-se também que a aprendizagem para a avaliação pode ser representada na base de uma concepção intermédia (quando a avaliação é vista como uma atividade que conjuga a memorização com a compreensão) e como forma de obter classificações, o que corresponde à concepção institucional proposta por Biggs (1989, 1990) e Biggs e Moore (1993). A aprendizagem para a avaliação foi representada, ainda, como um processo autorregulatório, que aponta para o planear e monitorar da ação, das tarefas, o autoavaliar e o retificar dos procedimentos.

Rebelo (2005), em um estudo com alunos portugueses do $1^{\circ}$ ao $4^{\mathrm{o}}$ ano de uma Licenciatura em Ciências da Educação, que pretendeu mapear as concepções de aprendizagem com o computador, registrou a presença de uma concepção quantitativa, quando o aprender com o computador é visto enquanto acumulação de informação por memorização. Verificou, também, a presença de uma concepção qualitativa, quando o aprender com o computador é tido como um processo de compreensão e/ou transformação do conhecimento, o que poderia resultar numa mudança pessoal. Registrou, ainda, uma concepção institucional, quando o aprender com o computador é visto como um auxílio na obtenção de trabalhos de qualidade e classificações mais elevadas.

Freire (2008), num estudo que procurou caracterizar as concepções de aprendizagem de estudantes universitários brasileiros, demonstrou uma replicação da maioria das concepções de aprendizagem descritas pela investigação fenomenográfica (i.e. a distinção entre aprendizagem enquanto memorização e enquanto compreensão). Surgiram também concepções aparentemente novas (i.e. aprender é desenvolver concepções sobre as matérias, decorar e 
aplicar o conhecimento adquirido; aprende-se com os erros; aprendese pelas/com as emoções ou empatia; aprende-se sem exercer qualquer intenção ou esforço e aprende-se de forma instintiva ou inata).

Van den Brink e colaboradores (2000, apud Duarte, 2004) detectaram indícios de que os estudantes representam o computador em termos quantitativos, qualitativos e institucionais. Essas variações sugerem que o computador pode ser concebido como um instrumento que atualiza uma concepção previamente estruturada (DUARTE, 2000).

Em relação à leitura, também é possível distinguir uma concepção quantitativa, quando a tarefa é imposta exteriormente e quando os leitores são vistos como "[...] recipientes vazios, a encher com palavras das páginas” (MARTON e SÄLJÖ, 1984, p. 40), e de uma concepção qualitativa, quando a leitura é vista como um meio para conhecer, envolvendo o confronto da perspectiva do autor e do leitor (SÄLJÖ, 1984).

Relativamente à escrita, é possível diferenciar uma concepção "não interpretativa", quando essa é entendida como um instrumento para corresponder às exigências institucionais, sendo tida como recolha e reprodução não seletiva da informação, quando o texto é ordenado de forma simples e discreta e quando não existe um ponto de vista explícito; de uma concepção "interpretativa", quando a escrita é vista como um meio de aprendizagem e expressão subjetiva, dirigindo-se a uma estruturação integrada de um argumento pessoal (HOUSELL, apud DUARTE, 2000).

Concernentemente aos níveis acadêmicos, as concepções de aprendizagem parecem progredir com o avanço no percurso escolar. Lonka e Lindblom-Ylänne (1996, apud Duarte, 2000) sugeriram que os novatos numa matéria ou numa fase de escolaridade podem começar apresentando uma concepção quantitativa, possivelmente de modo a construírem uma base de informações, antes de investirem nos processos de interpretação e compreensão. Marton e Colaboradores (1993) também referiram que as concepções tornam-se mais sofisticadas na medida em que aumenta a frequência ou avança-se nos estudos.

As concepções de aprendizagem também parecem estar associadas à "epistemologia pessoal”. A uma concepção quantitativa se associaria uma visão do conhecimento dualista, ou seja, é encarado 
como uma coleção de fatos e competências discretas e já feitas, a espera de serem descobertas por alguém. Assim, aprender seria transferir tais unidades discretas para dentro da cabeça. Em contrapartida, a uma concepção de aprendizagem qualitativa se associaria uma visão do conhecimento relativista, na qual o conhecimento é encarado como algo em progressiva construção. Por seu turno, a uma concepção institucional se associaria uma visão do conhecimento como algo que é elaborado e expandido por instituições especializadas de acordo com os padrões acordados (RYAN, 1984, apud DUARTE, 2000).

Van Rossum e Shenck (1984, apud DUARTE, 2004) verificou que relativamente ao gênero sexual, as moças tendem a uma concepção quantitativa, enquanto os rapazes não apresentam nenhuma tendência significativa.

O incremento das concepções de aprendizagem também está relacionado a uma sofisticação progressiva da própria aprendizagem. O aprender se desenvolve ao longo do tempo e da experiência, passando de uma concepção quantitativa, quando a aprendizagem é vista como óbvia; a uma concepção qualitativa, quando a aprendizagem pode ser alvo de reflexão e discussão (SÄLJÖ, 1979, apud DUARTE, 2004). Inicialmente, os estudantes procuram desenvolver uma noção da aprendizagem baseada na cultura, antes de procurarem desenvolver uma noção pessoal, mudando a noção inicial. Da mesma forma, quando o todo está em falta é provável que a aprendizagem também falhe, é o que acontece quando um grupo de crianças não consegue aprender a ler e escrever porque a cultura a qual pertencem não valoriza tais procedimentos (ASHTON-WARNER,1963, apud DUARTE, 2000).

As concepções também têm sido relacionadas com variáveis contextuais. A uma concepção quantitativa se associaria um contexto de ensino-aprendizagem fechado, no qual o professor detém o poder e a responsabilidade (DUARTE, 2000), possuindo uma concepção do mesmo tipo, apresentando os conteúdos como unidades de informação a memorizar e reproduzir (DUARTE, 2000) e oferecendo com uma freqüência alta, atividades que retiram a possibilidade de investir e refletir de forma profunda (HOUNSELL, 1984, apud DUARTE, 2000). Por sua vez, a uma concepção qualitativa se associaria um contexto 
aberto, promotor de um espírito crítico, com a exposição de múltiplos pontos de vista (MARTON et al., 1993), com métodos de ensino e tarefas estimuladoras da inter-relação entre as matérias (DEJONG, 1994, apud DUARTE, 2000) e incentivadoras da compreensão e mudanças pessoais (DUARTE, 2000).

Também foi sugerido que contextos que defendem uma prática de aprendizagem/ensino baseada em currículos e sistemas de avaliação muito rígidos podem contribuir para a construção e manutenção de concepções mais quantitativas (DUARTE, 2000). Da mesma forma, elementos de um contexto cultural alargado, com concursos televisivos que parecem traduzir uma noção de aprendizagem enquanto aquisição e reprodução de respostas certas, também dificultariam a promoção de concepções de aprendizagens mais qualitativas (DUARTE,2000).

Relativamente à proporção das concepções de aprendizagem, os estudos têm sugerido que uma parte significativa dos estudantes tende a uma concepção mais quantitativa (DAVIES, 1995, apud DUARTE, 2000).

\section{As Dimensões das Concepções de Aprendizagem}

Pramling (1983) identifica dois aspectos nas concepções de aprendizagem: o primeiro relaciona-se à noção daquilo que é aprendido (o que é a aprendizagem) e o segundo refere-se à forma como a aprendizagem se realiza (como se aprende). Dahlin e Regmi (1997), procurando organizar as seis categorias de Marton e colaboradores (1993), sugeriram a representação das concepções de aprendizagem em duas dimensões: "Profundidade" (i.e. o "signo" ou "significado") referente ao objeto e "temporal" (i.e. aquisição, conhecimento ou aplicação) relativa à fase da aprendizagem. Duarte (2000), buscando conjugar e simplificar as dimensões sugeridas acima, propôs cinco dimensões para analisar as concepções de aprendizagem: a dimensão referencial, que é o aspecto central e implica a definição de um conceito (o que é a aprendizagem); a dimensão processual, que se refere ao modo como os estudantes realizam a aprendizagem (como se aprende); a dimensão contextual, que se relaciona ao momento, o lugar, às 
circunstâncias ou intervenientes da aprendizagem (quando, onde, com quem e em que circunstâncias se aprende); a dimensão funcional, que se refere às consequências ou às funções da aprendizagem (para quê se aprende); e a dimensão fatorial, que engloba os fatores aliciadores, inibidores e ou os obstáculos da aprendizagem (quais são os fatores envolvidos na aprendizagem).

Nesse estudo, propomos uma reflexão sobre as concepções de aprendizagem do ponto de vista da teoria fenomenográfica. Procuramos confirmar a ideia de que o aprender é um fenômeno complexo, sujeito à influência de uma gama de fatores, e que embora seja um elemento comum à espécie humana, as pessoas diferem bastante na forma de conceber e se relacionar com a aprendizagem. Sabe-se que a aprendizagem acadêmica é um processo vital para a adaptação e o desenvolvimentos das pessoas. Uma oportunidade não só de dominar conhecimentos, mas de compreendê-los, e mais que isso, uma oportunidade para mudar qualitativamente como pessoa. A aprendizagem não é apenas um produto genético, mas também um produto cultural. As relações estabelecidas entre estudantes, professores, materiais e ambientes derivam de organizações sociais. Acontece que a formação e educação demandam posturas voltadas para uma relativização do conhecimento. Não se trata apenas de adaptar o estudante à aprendizagem, mas também de modificar os ambientes em função das nossas concepções de aprendizagem. Sem uma reflexão sobre as concepções de aprendizagem, ela própria favorecedora de uma maior autorregulação do estudante, as demandas atuais, com seus "turbilhões" ultrapassarão em muito a capacidade de aprender.

O objetivo desse estudo consistiu em demonstrar a proeminência de quem aprende, pois como postula a Fenomenografia, subjacente a forma de se comportar em relação a um fenômeno, está a forma como o concebemos. Assim, é importante descobrir e, se necessário, intervir sobre as concepções de aprendizagem, porque melhorias nos sistemas educativos implicam não só mudanças objetivas, mas mudanças nos modos de perceber os fenômenos. A questão que se coloca não é mudar concepções mais qualitativas em detrimento de concepções mais quantitativas. Estas últimas, muitas vezes, podem ser mais eficazes 
em relação aos resultados acadêmicos. O problema consiste em conceber a aprendizagem apenas e somente como uma atividade memorística, ou seja, quando o estudante considera que a aprendizagem independe de processos reflexivos, pois, de alguma forma, suas necessidades têm sido mantidas, seja porque os professores que têm ou tiveram adotam métodos estereotipados, seja porque as tarefas específicas não requerem níveis de abstração mais elevados.

O relatório da Comissão Internacional sobre educação para o Século XXI (1996) para a Unesco sugere que a educação deve ter como pilares "aprender a conhecer"; "aprender a fazer"; "aprender a ser" e "aprender a viver juntos"; dado que confirma a necessidade das aprendizagens deixarem de se centrar apenas em objetivos de transmissão dos conhecimentos e avaliação da sua reprodução e passarem a se centrar na construção das personalidades.

Estando envolvido com o ensino e a aprendizagem acadêmica, seja como estudante, professor ou psicólogo, não pude deixar de conceber esse trabalho como uma tarefa que visou à necessidade intrínseca do esclarecimento, sempre limitado, da realidade subjetiva de quem aprende. Desejo ter contribuído para clarificar teoricamente o campo das concepções de aprendizagem, para alertar para a necessidade de mais investigações nessa área, e para que nós, professores, estudantes e demais envolvidos nos processos de educação possamos melhorar as nossas práticas de ensino-aprendizagem.

\section{Notas}

\footnotetext{
${ }^{1}$ Psicólogo, professor, especialista em Psicologia Organizacional e do Trabalho pela UNICAP - Universidade Católica de Pernambuco, mestre em Ciências da Educação e doutorando em Psicologia da Educação pela FPCE - Faculdade de Psicologia e de Ciências da Educação da Universidade de Lisboa, Portugal, é investigador do Projeto de Documentação Histórica "Resgate: Barão do Rio Branco" do Ministério da Cultura do Brasil, no Arquivo do Instituto de Investigação Científica Tropical "Histórico Ultramarino" de Lisboa.Universidade deLisboa (luizgustavolfreire@ig.com.br)

${ }^{2}$ Para uma análise mais detalhada sobre estratégias de aprendizagem, veja-se Veiga Simão (2002).

${ }^{3}$ Já em 1580, Montaigne (apud Monteiro, 2005) estabeleceu uma diferenciação entre uma aprendizagem memorística e uma aprendizagem que apreendesse o "sentido e a substancia”.
} 
${ }^{4}$ Arquimedes (287-212 a.C. cit. na Grande enciclopédia Universal, 2004) compreendeu que um sólido mergulhado num líquido sofre uma impulsão vertical de baixo para cima, igual ao peso do líquido deslocado pelo corpo.

${ }^{5}$ Para uma análise mais detalhada sobre o papel e os tipos das motivações nas aprendizagens, veja-se Sá (2004) e Lemos (2005)

\section{Referências}

BOWDEN, J. et al. Displacement, velocity and frame of reference: phenomenographic studies of students' understandings and some implications for teaching and assessment. American Journal of Physics, n.60, 1992.

BOWDEN, J.; MARTON, F. The university of learning. Routledge Falmer, 2004.

CLIFF, A. Teacher-learners' conceptions of learning: evidence of a "communalist" conception amongst postgraduate learners? Higher Education, n. 35, 2, 1998, p. 205-220.

DAHLIN, B.; REGMI, M. Conceptions of learning among nepalese students. Higher Education, n. 33, 4, 1997, p. 471-493.

DUARTE, A. Avaliação e modificação de concepções, motivações e estratégias de aprendizagem em estudantes do ensino superior (Tese de Doutoramento), Lisboa: Faculdade de Psicologia e Ciências da Educação da Universidade de Lisboa, 2000.

DUARTE, A. Aprendizagem, ensino e aconselhamento educacional: uma perspectiva cognitivo-motivacional. Porto: Porto Editora, 2002.

DUARTE, A. Concepções de aprendizagem em estudantes universitários (as) portugueses (as). Revista Portuguesa de Psicologia,n. 18, 1, 2004, p. 147-163. 
ENTWISTLE, N. Contrasting perspectives on learning. In F. Marton, D. Hounsell, N. Entwistle (ed.). The experience of learning. Edinburgh: The Scottish Academic Press, 1984.

FREIRE, L. G. L. Concepções de aprendizagem em estudantes universitários brasileiros (Tese de Mestrado). Faculdade de Psicologia e Ciências da Educação da Universidade de Lisboa, 2008.

FREIRE, P. Educação e mudança. São Paulo: Editora Paz e Terra, 2003.

GIORGI, A. A phenomenological perspective on certain qualitative research methods. Journal of Phenomenological Psychology, n. 25, 2,1994, p. 190-220.

GRÁCIO, M. Concepções do aprender em estudantes de diferentes graus de ensino: do final da escolaridade obrigatória ao ensino superior: uma perspectiva fenomenográfica. Évora: Universidade de Évora, 2002.

MARTON, F. On non-verbatim learning - IV: Some theoretical and methodological notes. Scandinavian Journal of Psychology, n. 17,1976, p. 125-128.

MARTON, F. Phenomenography - describing conceptions of the world around us. Instituctional Science, n.10, 1981, p.177-200.

MARTON, F. Beyound individual differences. Educational Psychology, n.3 (3-4), 1983, p. 289-303.

MARTON, F. Phenomenography - A research approach to investigating different understandings of reality. Journal of Thought, n. $21,(3), 1986$, p. $28-49$.

MARTON, F. Describing and improving learning. In R. Schmeck (ed.), Learning strategies and learning styles. New York: Plenum, 1988. 
MARTON, F; Booth, S. Learning and awareness. Mahwah: Lawrence Erlbaum, 1997.

MARTON, F; DALL'ALBA, G; BEATY, E. Conceptions of learning. International Journal of Educational Reserch, n. 19, 3, 1993, p. 277-300.

MARTON, F.; FAI, P. Two faces of variation. Paper presented at $8^{\text {th }}$ European conference for learning on instruction. Göteborg: Göteborg University, August, 24-28, 1999.

MARTON, F; SÄLJÖ, R. On qualitative differences In learning - I. Outcome and process. Brittish Journal of Educational Psychology, n.46,1976, p. 4-11.

MARTON, F.; SÄLJÖ, R. Approaches to learning. In F. Marton, Hounsell e N. Entwistle (ed.) The experience of learning. Edinburgh: Scottish Academic Press, 1984.

MARTON, F; SÄLJÖ, R. Approaches to learning. In F. Marton, Hounsell e N. Entwistle (ed.) The experience of learning. Edinburgh: Scottish Academic Press Limited,n. 39-58, 1997.

NORTON, L.; CROWLEY, C. Can studentes be helped to learn how to learn? an evaluation of an approches to learning programme for first year degree students. Higher Education, n.29, 1995, p. 307328.

NORTON, L.; DICKKINS, T. Do approaches to laearning courses improve students' learning strategies? In G. Gibbs (ed.), Improving student learning: theory and practice. Oxford: The Oxford Centre for Staff Development, 1995.

PRAMLING, I. The childs conception of learning. Göteborg: Acta Universitatis Gothoburgensis, 1983. 
REBELO, M. Concepções de aprendizagem com o computador em estudantes universitários (Tese de Mestrado). Faculdade de Psicologia e Ciências da Educação da Universidade de Lisboa, 2005.

RENDEIRO, A. Concepções de aprendizagem para a avaliação em estudantes do ensino secundário (Tese de Mestrado). Faculdade de Psicologia e Ciências da Educação da Universidade de Lisboa, 2005.

RICHARDSON, J. The concept and methods of phenomenographic research. Review of Educational Research, n. 69, 1, 1999,p.11-23.

ROSÁRIO, P; ALMEIDA, L. Leituras construtivistas da aprendizagem. In: G. MIRANDA; S. BAHIA, (orgs.), Psicologia da Educação: temas de desenvolvimento, aprendizagem e ensino. Lisboa: Relógio D’Água Editores,2005, p. 141-165.

ROSÁRIO, P. et al. Discursos de pais e alunos sobre o aprender: um estudo no $5^{\circ}$ ano de escolaridade. Psicologia em Estudo. Consultado em 08/10/2007: Disponível em: http://www.scielo.br/ scielo.php?pid=S1413-73722006000300002\&script=sci_arttext

SÄLJÖ, R. Learning and understanding: a study of diferrences In constructing meaning from a text. Göteborg: Acta Universitatis Gothoburgensis, 1982.

SÄLJÖ, R. Learning from reading. In: F. MARTON, HOUNSELL e N. ENTWISTLE (ed.) The experience of learning. Edinburgh: Scottish Academic Press, 1984.

UNESCO. Relatório para a unesco da comissão internacional sobre educação para o século XXI. In Delors, J. (Coord.), Educação um tesouro a descobrir. Edições Asa, 1996. 


\section{Fenomenographic theory and conceptions of learning}

Résumé: L'objectif de cet article est promouvoir des réflexions concernants a les conceptions d'apprentissage, en faisant des références par la théorie "phenomenegraphique", pour bien perfeccioner les pratiques de enseignement-apprentissage.

Mots clé: conceptions,; apprentissage,; phenomenographie".

Recebido em: Março/2009

Aceito em: Maio/2009 
